\title{
Studying prevention of parent to child transmission services, interventions, coverage and utilization
}

\author{
Seema Patel*, Nikhil Anand \\ Department of Obstetrics and Gynecology, GMERS Medical College, Sola, Ahmedabad, Gujarat, India \\ Received: 01 May 2019 \\ Accepted: 01 June 2019 \\ *Correspondence: \\ Dr. Seema Patel, \\ E-mail: drkalpesh1974@yahoo.com \\ Copyright: (c) the author(s), publisher and licensee Medip Academy. This is an open-access article distributed under \\ the terms of the Creative Commons Attribution Non-Commercial License, which permits unrestricted non-commercial \\ use, distribution, and reproduction in any medium, provided the original work is properly cited.
}

\begin{abstract}
Background: Human immunodeficiency virus (HIV) infection is increasing at an alarming rate globally. Apart from heterosexual route, mother to-child transmission is the next most important route of HIV transmission accounting for over $90 \%$ of infections in children. The present retrospective study is undertaken to evaluate the effectiveness of implementation of PPTCT programmed in GMERS Medical College, Sola, Ahmedabad, Gujarat, India.

Methods: At ICTCs, registered ANCs are counseled and tested for HIV. HIV+ve ANCs are linked to services and followed-up for institutional delivery. Antiretroviral prophylaxis with nevirapine was given to seropositive motherbaby pairs during delivery and children testing. HIV+ve ANCs since 2014 to 2016 subsequently delivered till December 2018 and their exposed children followed up till 18 months for confirmation of their seropositivity status in PPTCT were study at GMERS medical college, sola, Ahmedabad, Gujarat, India.

Results: 13595 ANCs registered, $100 \%$ were counseled pre-test, and $99.5 \%$ of them tested, $79.5 \%$ were counseled post-test. CD4 testing was carried out in all HIV+ve ANCs. 55 ANCs were detected HIV+ve inclusive of 37 new registered, 16 re-pregnancy and 2 unregistered cases. 55 pregnancy outcomes reported institutionally total $85.9 \%$ delivered at institute out of them $26.5 \%$ were caesarian sections and $62.4 \%$ delivered vaginally. Out of 48 live births, 47 sdNVP-MB-Pair were given. 48 children were traced till 18 months, $82.5 \%$ of live births were alive, and $68.75 \%$ of live births were tested. 1 was found HIV+ve with history of adherence to all prescribed PPTCT guidelines.

Conclusions: PMTCT services - counseling and testing should be provided to all ANCs. EDD-based tracking, institutional deliveries, postnatal counseling to be encouraged along with complete MB pair coverage, capacity building of concerned staff regarding delivery of HIV+ve ANCs and exposed children tracking.
\end{abstract}

Keywords: HIV in exposed children, HIV testing of pregnant women, MB pair, PMTCT, Antiretroviral therapy, Nevirapine, Seroprevalence

\section{INTRODUCTION}

AIDS (Acquired Immunodeficiency Syndrome) caused by Human Immunodeficiency Virus (HIV) is a major threat to the global health and development. In India, Human Immunodeficiency Virus (HIV) epidemic now is in fourth decade and has the heterogeneity. The epidemic pattern had shifted from highest risk groups to bridge population and then to general population. The trend indicated HIV infection spreads from high risk behaviour groups to general population. The principal mode of HIV spread is through heterosexual activity; however, the vast majority of children acquire the infection by mother tochild transmission (MTCT) which may occur during pregnancy, labor and delivery or through breast feeding. Mother to child transmission of HIV (MTCT) is the largest source of HIV infection in children below 15 years of age. ${ }^{1}$ According to NACO, about 30,000 infants 
are estimated to acquire HIV infection each year. ${ }^{2}$ Infection to newborns is transmitted by mother perinatally; however, considering the role of the male partner in the transmission of infection to a woman, in India it is appropriately termed as parent to child transmission (PTCT).

The vertical transmission of HIV infection without any intervention is reported in 25 to $35 \%$ of infants born to HIV positive women in Asia. ${ }^{1}$ Effective MTCT interventions can reduce vertical transmission to $1 \%$ or less. ${ }^{3}$ In India during, 2010-2011, 6.6 million pregnant women were counseled and tested and 16,954 HIV positive women were identified. ${ }^{4}$ HIV counseling and voluntary antenatal testing is an entry point cost effective intervention to detect HIV infection and to prevent transmission to the offspring.

Accordingly, the data generated from antenatal women has been used to monitor the trends in the general population and to predict to the seroprevalence in young women. ${ }^{5}$ Identification of the women with HIV infection during pregnancy allows women to take an informed decision about continuing the pregnancy and timely appropriate interventions to decrease the risk of MTCT.

In view of the above facts, the present study has been carried out to determine the seroprevalence of HIV infection among antenatal women, obstetric interventions, follow-up of mother and child, infant feeding options and testing of infants at 18 months of age as per National AIDS control organization (NACO) guidelines. ${ }^{6}$

\section{METHODS}

This observational study was conducted in department of obstetrics and gynecology of GMERS medical college Sola, Ahmadabad, Gujarat, India.

Study design was retrospective in nature by collecting data of the ante natal care clinics of the hospital. The data was collected for 3 years from January 2014 to December 2016 from ANC register and hospital registration system. All pregnant women attending the antenatal clinic for consultation and those coming directly for delivery in the hospital were taken into consideration.

Altogether 13595 from antenatal registration and 814 from direct labour for delivery mothers had enrolled in the hospital during the period of 2014 to 2016 subsequently delivered till December 2018 and their exposed children in PPTCT were study at GMERS Medical College, Sola, Ahmedabad, Gujarat, India.

Routine offer of HIV counseling and testing to all pregnant women enrolled into the antenatal care was done. Pregnant women were tested for HIV by Rapid test. All patients were again provided post-test counseling While seronegative pregnant women are counseled on
HIV prevention and risk reduction behavior, HIV seropositive pregnant women are additionally provided psychosocial support on disclosure issues and spousal testing, linkage to TB testing and ART services, importance of institutional delivery and intrapartum sdNVP, postpartum follow-up, and infant feeding.

During the delivery of these seropositive pregnant women, sdNVP regime of ARV (200 mg tab.) is given to the woman at the onset of labor and NVP syrup $(2 \mathrm{mg} / \mathrm{kg}$ of body weight) is offered to the babies within $72 \mathrm{~h}$ of the birth. $^{7}$

All the babies born to positive women received nevirapine prophylaxis for 6 weeks. Mothers were counseled regarding breast feeding.

Exposed children are tested at the completion of 18 months through HIV rapid tests for seropositivity confirmation. $^{8}$

\section{Statistical analysis}

Data analysis was done with software SPSS version16.0. Maternal and infant characteristics were compared using the chi-square test.

\section{RESULTS}

According Figure 1, PPTC services, during the study period from January 2014 to December 2016, in PPTCTICTC at GMERS Medical College, Sola, Ahmedabad, Gujarat, India, out of 13595 new antenatal booking visits, all women attended pre-test counseling and 13532 women consented for testing with acceptance rate of $99.5 \%$. Out of 13532 women tested, 37 were found to be HIV seropositive showing seroprevalence of $0.27 \%$. During study period 814 test done direct in labour room for unregistered patient out of them $2(0.24 \%)$ were seropositive. Overall seroprevalence is $0.33 \%$.

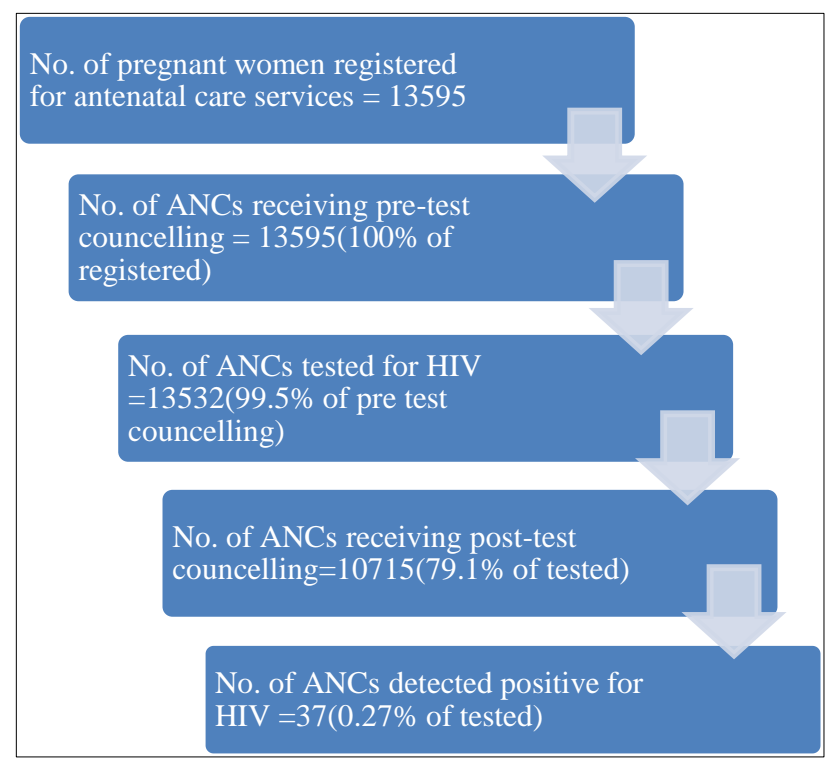


Figure 1: PPTC services.

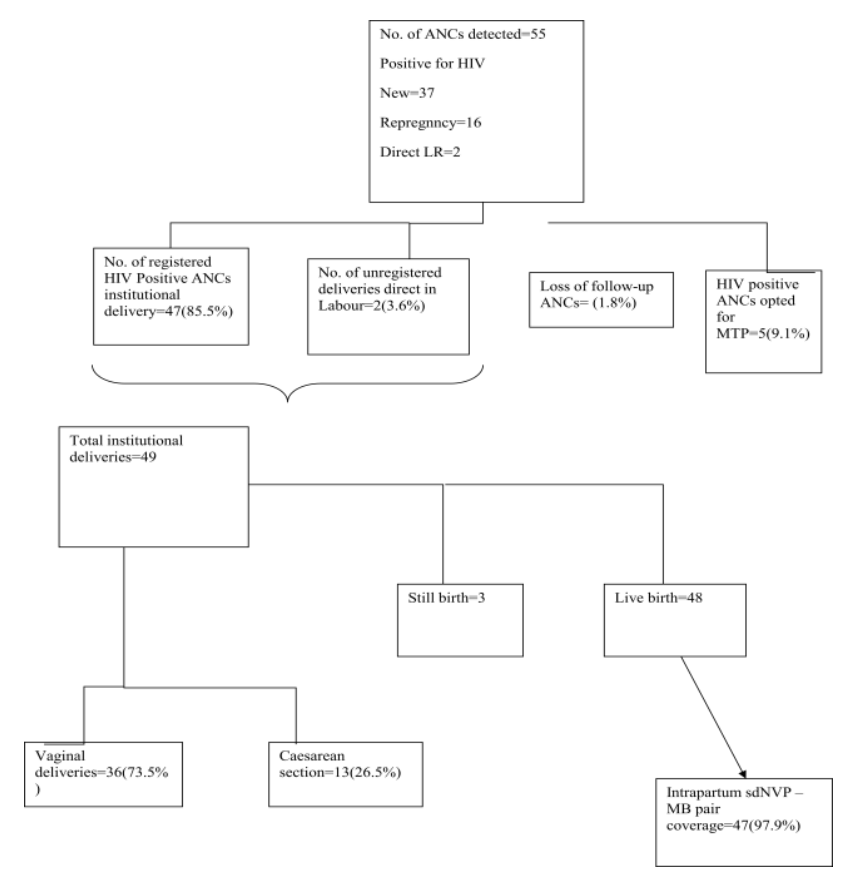

Figure 2: PPTC services and intervention.

During study period in PPTCT-ICTC the flow of ANCs tested for HIV along with pre- and posttest counseling, ANCs tested HIV seropositive, and direct-in-labor cases and their pregnancy outcomes along with sdNVP motherbaby (MB) pair coverage were found, there were 37 new ANCS registered, 16 have repregnancy and 2 came direct during labour. Out of 55 seropositive women, 5 had opted for medical termination of pregnancy.

During these 3 years of study, total no. of positive deliveries was 49 . Vaginal delivery took place in 36 cases (73.5\%) and LSCS was performed in13 cases (26.5\%) only for obstetric indications. Out of 49 deliveries there were 48 live births and 3 were still births and 2 twins deliveries, one of them has 2 live born and other had one live and one still born child. All mothers during labour and all live born babies were given nevirapine except one who delivered.

A total of $89.1 \%$ of all HIV+ve ANCs belonged to the 18-30 year age group. Primigravida were $32.8 \%$, primipara was $38.1 \%$ and multipara were $29.1 \%$.

Table 1: The demographic characteristics among HIV seropositive women.

\begin{tabular}{|c|c|c|c|}
\hline Variables & & No. of seropositive women & $\%$ \\
\hline \multirow[t]{2}{*}{ age } & $20-30$ & 49 & 89.1 \\
\hline & $31-40$ & 6 & 10.9 \\
\hline \multirow[t]{3}{*}{ parity } & 0 & 18 & 32.8 \\
\hline & 1 & 21 & 38.1 \\
\hline & $\Rightarrow 2$ & 16 & 29.1 \\
\hline \multirow[t]{4}{*}{ literacy } & illiterate & 24 & 43.6 \\
\hline & Just literate & 21 & 38.2 \\
\hline & Primary education & 6 & 11 \\
\hline & Secondary education & 4 & 7.2 \\
\hline \multirow[t]{3}{*}{ husband } & seropositive & 38 & 69.2 \\
\hline & NR & 14 & 25.4 \\
\hline & Not tested & 3 & 5.4 \\
\hline \multirow[t]{3}{*}{ trimester } & first & 18 & 32.7 \\
\hline & second & 20 & 36.3 \\
\hline & third & 17 & 31 \\
\hline \multirow[t]{4}{*}{ Marital status } & Married (1-5 years) & 35 & 63.6 \\
\hline & Married (5-10 years) & 11 & 20 \\
\hline & Married >10 years & 9 & 16.4 \\
\hline & widow & 3 & 5.4 \\
\hline
\end{tabular}

$43.6 \%$ of all HIV+ve ANCs were illiterate and the rest had got at least primary education or more.

Spousal counseling and subsequent HIV testing was successfully carried out in 52 cases $(94.5 \%)$. Thirty eight (69\%) couples were found to be concordant couples.
A total of $31 \%$ of HIV+ve ANCs were detected first time during their third trimester, $36.3 \%$ were detected in their second trimester, and $32.7 \%$ in the first trimester; $32.8 \%$ of detected HIV+ve ANCs were nulliparae. Active married life of 1 to 5 years in case of $63.6 \%$ of HIV+ve ANCs, $20 \%$ had 5-10 years while $16.4 \%$ of HIV+ve ANCs had an active married life of $>10$ years. Out of 55 HIV-positive ANCs (HIV+ve ANCs) 53 were married at 
the time of detection and 3 were widow. Out of 3 widows

1 had active married life of one year and two had 7 years.

Table 2: Year wise seropositive antenatal women registered, ounselled, tested.

\begin{tabular}{|c|c|c|c|c|c|c|c|}
\hline \multirow[t]{2}{*}{ Year wise services at institute } & & \multicolumn{2}{|l|}{2014} & \multicolumn{2}{|l|}{2015} & \multicolumn{2}{|l|}{2016} \\
\hline & & $\begin{array}{l}\text { No. of } \\
\text { ANCS }\end{array}$ & $\begin{array}{l}\text { Direct } \\
\text { LR }\end{array}$ & $\begin{array}{l}\text { No. of } \\
\text { ANCS }\end{array}$ & $\begin{array}{l}\text { Direct } \\
\text { LR }\end{array}$ & $\begin{array}{l}\text { No. of } \\
\text { ANCs }\end{array}$ & $\begin{array}{l}\text { Direct } \\
\text { LR }\end{array}$ \\
\hline $\begin{array}{l}\text { No. of seropositive women } \\
\text { detected }\end{array}$ & & 12 & - & 19 & - & 22 & 2 \\
\hline Institutional deliveries & Total & 9 & - & 18 & - & 20 & 2 \\
\hline & $\mathrm{CS}$ & 3 & - & 5 & - & 5 & - \\
\hline & Vginal deliveries & 6 & - & 13 & - & 15 & 2 \\
\hline MTP & & 3 & - & - & - & 2 & - \\
\hline Lost to follow up & & - & - & 1 & - & - & - \\
\hline No. of live births & & 9 & - & 17 & - & 19 & 3 \\
\hline No. of SB & & - & - & 1 & - & 2 & - \\
\hline $\begin{array}{l}\text { No. of MB pair coverage with } \\
\text { ARV prophylaxis }\end{array}$ & & 9 & - & 16 & - & 19 & 3 \\
\hline
\end{tabular}

The year-wise analysis of PPTCT services indicates the improved rate of detection and rate of institutional deliveries in HIV+ve ANCs. Simultaneously, the rate of MB pair coverage in live births against the detection of HIV+ve ANCs has been around 97.9\% which suggests the preparedness and good quality of counseling at the ICTC.
Shows tracing of 48 exposed during the tracking time, 8 babies $(16.6 \%)$ were lost to follow up 7 babies(17.5\%) reported dead. 33 live babies $(82.5 \%)$ trace up to 18 months and tested exposed children found HIV negative 32(96.9\%) and exposed children found HIV positive $=1(3.1 \%)$.

Table 3: Follow-up of the cohort of exposed children (children born to HIV +ve mothers = exposed children).

\begin{tabular}{|c|c|c|c|c|}
\hline \multirow{2}{*}{ Factor } & & & \multicolumn{2}{|c|}{ HIV seropositivity status in exposed children } \\
\hline & & & Total & HIV seropisitive \\
\hline \multirow{2}{*}{ SdNVP (MB pair) } & \multicolumn{2}{|l|}{ Received } & $47(97.9 \%)$ & $1(2.1 \%)$ \\
\hline & \multicolumn{2}{|l|}{ Not received } & $1(2.1 \%)$ & - \\
\hline \multicolumn{3}{|l|}{ Total delivery } & 49 & $1(2.04 \%)$ \\
\hline \multirow{2}{*}{ Mode of delivery } & \multicolumn{2}{|c|}{ Cesarean section } & $13(26.5 \%)$ & $1(7.6 \%)$ \\
\hline & \multicolumn{2}{|c|}{ Vaginal delivery } & $36(73.4 \%)$ & - \\
\hline \multirow[t]{2}{*}{ History of breast feeding } & \multicolumn{2}{|c|}{ Exclusive breast feeding } & $32(80 \%)$ & $1(3.1 \%)$ \\
\hline & \multicolumn{2}{|c|}{ Exclusive replacement feeding } & $8(20 \%)$ & - \\
\hline \multirow[t]{2}{*}{$\begin{array}{l}\text { Mother receiving ART } \\
\text { during the time of delivery }\end{array}$} & $\begin{array}{l}\text { ART } \\
\text { recommended }\end{array}$ & Mother on ART & $49(100 \%)$ & $1(2.04 \%)$ \\
\hline & & Mother not on ART & - & - \\
\hline
\end{tabular}

Table 4: Analysis of seropositive child.

\begin{tabular}{|lllll|} 
Seropositive child & MB pair & Mode of delivery & Breast feeding & Mother on ART \\
\hline 1 & Received & Cesarean section & Exclusive BF & $\begin{array}{l}\text { Mother on ART accordance with } \\
\text { recommendation }\end{array}$ \\
\hline
\end{tabular}

Out of total 49 deliveries $73.4 \%$ delivered vaginally and $26.5 \%$ requited cesarean section. One seropsitive child was delivered by CS. All these babies MB pair was given in each case. sdNVP was given to 46 mothers and 47 babies collectively. Excluding the MTPs and still births, in cases of 48 live births, sdNVP MB pair was given in 47 cases $(97.9 \%)$ and 3 of those MB pairs were given in direct-in-labor cases. 
Out of 48 live births 8 (exposed children), 20\% women chose alternatives of breastfeeding, like formula feeding; $80 \%$ women opted for exclusive breastfeeding.

The HIV+ve child was delivered by caesarean section and was on breastfed. ART was started antenatally to mother; MB pair was given as per the guidelines. The spouse was not tested because she was widow her active married life is 1 year and she registered during second trimester of pregnancy.

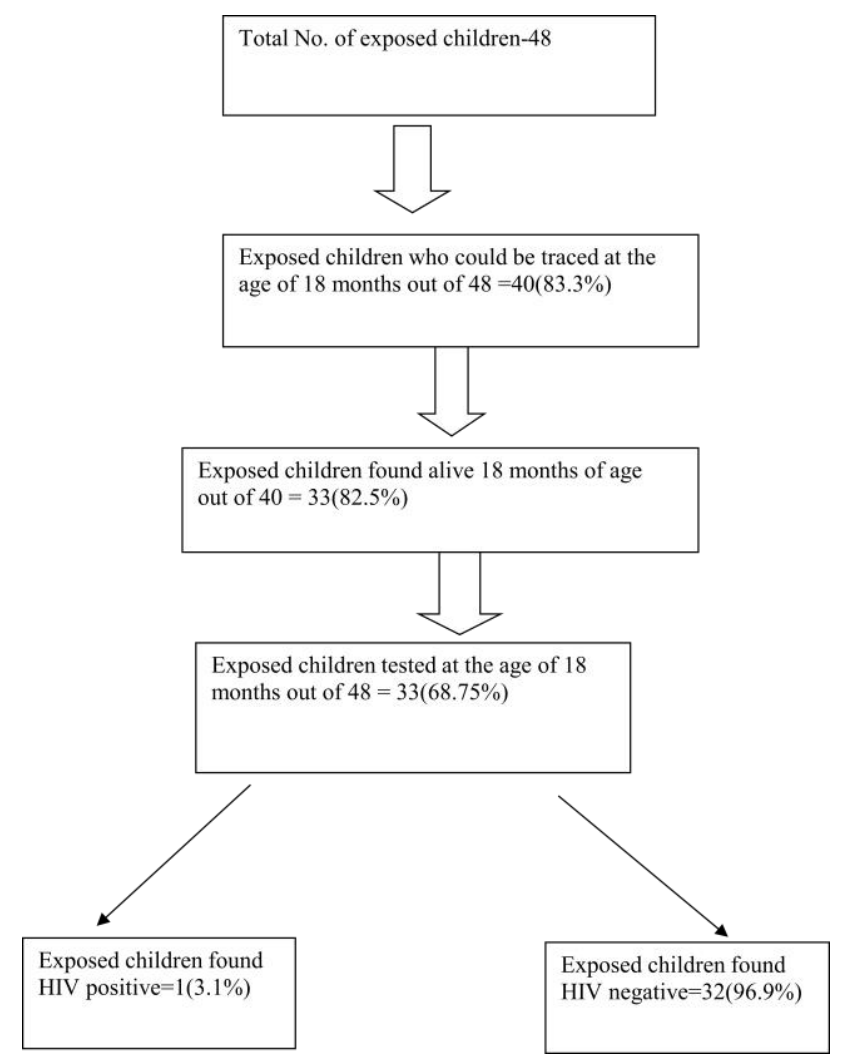

Figure 3: Tracing of exposed for 18 months.

\section{DISCUSSION}

The PPTCT center is well established for more than 10 years now and the service uptake in terms of pretest counseling of registered ANCs, testing of every counseled ANC, and subsequent posttest counseling is ever improving since the inception.

Posttest counseling is essential in bondage, follow-up, and institutional delivery. Its quality mainly depends upon skills and motivational levels of the counselor.

Seroprevalence was $0.27 \%$ in registered ANCs while it was $0.24 \%$ in unregistered direct-in-labor cases. Overall HIV seroprevalence was thus $0.33 \%$. HIV seroprevalence rate in antenatal cases in our study lower than the national average seroprevalence rate in antenatal cases of $0.35 \% .^{9}$ Vellanki VS et al, found seroprevalence of $1.12 \%$ and Kulkarni SK et al, found $0.76 \% .^{10,11}$ This wide variability in HIV seroprevalence among antenatal women may be attributed to the difference in health seeking and risk behaviors in different parts within and outside India which mostly depends on socio cultural milieu of the community.

Out of all 57 HIV+ve ANCs, 3.6\% were detected only at the time of delivery which shows the immense need to test not only registered ANCs but also the unregistered emergency cases in order to provide prophylactic sdNVP in due time. This also points at the need to identify and plug the gaps in integration with the $\mathrm{RCH}$ program to enhance early detection and linkage to care, support, and treatment.

Illiteracy in around two-thirds of the HIV+ve ANCs along with the major age group being 18 to 30 year old is a worrisome scenario. The notion of education-as-thesolution to majority of health problems of the country is applicable here as well. Awareness about safe sex and issues like women empowerment can go a long way in achieving the pertinent MDGs. Higher level of education and high socio-economic status could facilitate the spread of HIV awareness and increase the use of barrier contraceptives. ${ }^{12}$

Around $63.6 \% \mathrm{HIV}+\mathrm{ve}$ ANCs reporting their active married life of less than 5 years is a very serious issue when thought about in the context of the regular childbearing age of a woman of about 30 years. The infected woman throughout her reproductive age will be at risk of transmitting the virus both horizontally and vertically.

When all HIV+ve ANCs are reportedly married and $25.4 \%$ couples are still discordant, proper post-test counseling as well as during the follow-up visits and outreach activities pertaining to safe sex and promotion of condom can go a long way in further prevention of transmission.

The cornerstone of preventing vertical transmission is early ANC registration with immediate HIV testing which should be done in the first trimester. The study found such early registered HIV+ve ANCs was 32.7\%. The late detection of the seropositive status eventually makes every step of PPTCT services difficult including CD4 testing, ART initiation, nutrition advices, care, follow-up, and timely institutional admission for delivery. This requires special attention from the authorities in terms of developing specific behavior change communication (BCC) tools and their implementation.

More than half of HIV+ve ANCs had one or more child previously which adds to the existing possible viral pool and again corroborates with the aforementioned needs of conveying right messages about the importance of earliest HIV testing.

While $9.1 \%$ seropositive women opted to terminate their pregnancies in the first trimester, A study, conducted in 
West Bengal showed 12.24\% underwent MTP and another study showed $17.85 \%$ opting for MTP. ${ }^{13,14}$

Delivery by vaginal route took place in most of the cases $(73.5 \%)$ and LSCS was performed only for obstetric indications in $26.5 \%$ of cases. Our results are comparable with study by Saini VK et al, who found $40.74 \%$ seropositive women delivered vaginally and $37.6 \%$ women delivered by LSCS. ${ }^{15}$

One HIV+ve ANCs were not reported delivering institutionally which may be a case of delivering domestically or in private sector or loss to follow-up. Institutional delivery is the mainstay of PPTCT services especially for intrapartum ARV interventions and followup.

Simplicity, low-cost, and efficacy are the reasons why sdNVP prophylaxis as MB pair is widely used in resource-constrained settings of PMTCT globally as well as in India. ${ }^{7,16}$ The coverage of sdNVP to both mother and baby was reported in $97.9 \%$ of live births which ideally should have been $100 \%$. Nevirapine to any of them is considered to be resulting into decreased efficacy. Three of these MB pairs were given in direct-in-labor cases (out of total 47) which a significant achievement is considering the emergency conditions.

Maternal antibodies are expected to be present in the baby at least till 18 months of age; hence, rapid tests detecting antibodies are designated at 18 months. ${ }^{17}$ The follow-up of exposed babies is a difficult task even in urban settings considering migration and other social factors. Just like ANCs, drop-out in service utilization was observed among exposed children also.

A total of 40 out of 48 exposed children actually had been traced till 18 months $(83.3 \%)$ which can be a result only from good follow-up. Seven of those babies died by the time they reached the desired age, so theoretically, there were 33 babies in follow-up. A total of 33 babies were tested at 18 months and 1 was found to be HIV+ve, seroprevalence being 3.03\%. Parameshwari et al. in their study in Tamil Nadu reported 2 infants turning out to be positive out of 46 live births $(4.35 \%){ }^{18}$

Around $80 \%$ of HIV+ve mothers delivering live babies choosing exclusive breast feeding showed effectiveness of proper counseling. HIV virus is transmitted through breast milk. Transmission rates for breast feeding mothers may be as high as $30-40 \% .^{19}$

Breast feeding is not recommended for HIV infected women in developed countries, although WHO recommends breastfeeding with early weaning by 6 months for women living in developing countries where infectious diseases and malnutrition are the primary causes of infant death. ${ }^{20}$ In our hospital pregnant mothers and their families were counseled about best feeding options for their infants. Where women can accept, afford, sustain, feasible and safe avoidance of exclusive breast feeding $(\mathrm{EBF})$ is recommended. In our study, only $20 \%$ mothers opted for replacement feeding in the form of commercial formula or home prepared modified animal milk.

\section{CONCLUSION}

The HIV-seroprevalence rate among antenatal women was $0.33 \%$. The dropout rates of the positive mothers and their babies should improve. The interventions in PPTCT to significantly reduce perinatal transmission of HIV/AIDS can be successful if they are integrated with Maternal and Child Health (MHC) services. The protection from MTCT by nevirapine is encouraging. The mainstay of the PPTCT program is to counsel and offer HIV testing for all women registered for antenatal checkups, improving institutional delivery rates among

HIV positive women, administering SDNVP to motherbaby, safe delivery provided by the obstetrics unit with universal precautions, and good follow-up services to mother and baby.

Aggressive BCC measures about safe sex, STDs, condom promotion, and safe blood transfusion, especially directed to the newly married and younger couples as well as to the discordant couples can prove vital.

A threefold strategy is needed to prevent child from acquiring HIV infection from their mothers (i) by preventing HIV infection among prospective parents (ii) avoiding unwanted pregnancies among HIV seropositive women and (iii) preventing the transmission of HIV from HIV seropositive mothers to their infants during pregnancy, delivery and breast feeding.

What is of utmost importance is implementation of these strategies to prevent the acquisition of a lifelong infection which is largely preventable, thereby negating not only an important burden of mortality and morbidity, but also tremendous social stigma.

\section{ACKNOWLEDGMENTS}

Authors would like to thank Dr. Ajesh Desai, HOD Obstetric and Gynecology Department.

\section{Funding: No funding sources \\ Conflict of interest: None declared \\ Ethical approval: Not Required}

\section{REFERENCES}

1. UNAIDS: Prevention of HIV transmission from mother to child. Strategic options. Available at: http://www.unaids.org/html/pub/publications/ircpub05/prevention_en_pdf.pdf.

2. National AIDS Control Organization: Guidelines for the prevention of mother to child transmission of 
HIV. Available at http://www.nacoonline.org/ guidelines/guideline_9.pdf.

3. CDC.gov. Atlanta: Fact sheets: HIV among pregnant women, infants and children in the United States; c2012-13. Available at: http://www.cdc.gov/hiv/ topics/ perinatal/index.htm.

4. National AIDS Control Programme Phase IV: Working groups Reports- ICTC/PPTCT [internet]. Government of India: National Control Organization (NACO) c2007-. Available at: http://www.nacoonline.org.

5. Boerma JT. Estimates of HIV-1 prevalence from national population-based surveys as a new gold standard. Lancet. 2003;362:1929-31. Available at: http://dx.doi.org/10.1016/S0140-6736.

6. Laboratory diagnosis, biosafety and quality control. Government of India: National AIDS Control Organization (NACO). c2007. Available at: http://www.nacoonline.org.

7. NACO document. Available at: http://www. nacoonline.org/Miscellaneous/Prevention_of_Parent _to_Child_Transmission/.

8. NACO Guidelines for the prevention of mother to child transmission of HIV. Available at: http://www.naco.nic.in/pmtct.html.

9. Gupta S, Kumar D. A retrospective five years study of PPTCT programme in SMGS Hospital, Jammu. J Evolution Med Dental Sci. 2015;4:16554-7.

10. Vellanki VS. Seroprevalance of HIV in women attending antenatal clinic at KIMS hospital, Narketpall Int J Reprod Contracept Obstet Gynecol. 2012;1(1):17-21.

11. Kulkarni SK, Doibale MK. Trend of seroprevalence of HIV among antenatal clinic attendees at a tertiary care hospital. Int J Basic Applied Med Sci. 2013;3(1):257-62.

12. Glynn JR, Carael M, Buve A, Anagonou S, Zekeng L, Kahindo $M$, et al. Does increased general schooling protect against HIV infection? A study in four African cities. Trop Med Int Health. 2004;9:414.

13. Bal R, Talukdar A, Roy K. Prevention of parent to child transmission of HIV - scenario of West Bengal. J Obstet Gynecol India. 2008;58:221-5.
14. Prevention of mother to child transmission of HIV (MTCT). Available at: www.avert.org/motherchild. htm.

15. Saini VK, Sharma SV. A retrospective five years study of pptct programme in smgs hospital, Jammu. J Evolution Med Dent Sci. 2015;4(100):16554-7.

16. Government of India. Ministry of Health and Family Welfare. 6. National AIDS Control Organization (NACO). Prevention of parent to child transmission (PPTTC) of HIV India. Sensitization training curriculum presentation manual. New Delhi: NACO; 2004:41-56.

17. Interagency Task Team (IATT) on Prevention of HIV Infection in Pregnant Women, Mothers and their Children. 2006a. Joint Technical Mission to Support PPTCT Scale up and Paediatric Care Implementation in India, New Delhi, India, 2006.

18. Parameshwari S, Jacob MS, Vijayakumari J, Shalini D, Sushi MK, Sivakumar M. A program on prevention of mother to child transmission of HIV at Government Hospital, Tiruchengode Taluk, Namakkal District. Indian $\mathbf{J}$ Community Med. 2009;34:261-3.

19. Kourtis AP, Jamieson DJ, de Vincenzi I, Taylor A, Thigpen MC, Dao H, et al. Prevention of human immunodeficiency virus -1 transmission to the infant through breastfeeding: new developments. Am J Obstet Gynecol. 2007;197(3 suppl);S113-22.

20. WHO/UNICEF/UNFPA/UNAIDS. HIV Transmission through breastfeeding, a review of available evidence 2007 Update. Geneva: World Health Organization; 2008. Available at: http://whqlibdoc.who.int/publications/2008/9789241 596596_eng.pdf.

Cite this article as: Patel S, Anand N. Studying prevention of parent to child transmission services, interventions, coverage and utilization. Int J Reprod Contracept Obstet Gynecol 2019;8:2871-7. 